\title{
Short Note \\ Restoration of degraded land through Moso bamboo (Phyllostachys pubescens) plantation in the Mid-hills of Nepal
}

\author{
G. P. Gautam ${ }^{1 *}$, R. R. Aryal ${ }^{1}$ and P. Lamichhane ${ }^{1}$
}

Bamboo is basically a perennial grass with woody culms from rhizomes. The growth rate of bamboo is approximately $121 \mathrm{~cm}$ in $24 \mathrm{hrs}$, which is recorded as one of the fastest growth plant on earth (Ueda, 1974 cited by Adhikari, 2008). It matures within 3-5 years depending on the type of species, ecological as well as the prevailing edaphic and climatic factors. Due to its fast growing nature, it is acting as remedial materials for reducing land degradation through fast recovery. Bamboos have the dense surface root, large network of rhizomes which form a mat-like structure that prevent seepage of soil water and provide good protection during sheet and gully erosion for soil conservation (Stapleton, 1994; Narayana, 1988; Howell et al., 1989).

Land degradation results in decrease in land quality and its productivity which initiate longterm loss of ecosystem function caused by direct and indirect human induce disturbances from which the land cannot recover unaided (Bai et al., 2008). It is a major environmental problem in Nepal. Deforestation, shifting cultivation, overgrazing, steep slope farming, over use of chemical fertilizers and abandon of fallow land alter the bio-physical and chemical properties of land (Acharya and Kafle, 2009).Such human induced activities need to be altered to reclaim the degraded land. Mechanical approaches for degraded land restoration are not sustainable as compared to biological approaches which are economically sound due to better soil protection capacity. However, the combination of both approaches is effective in restoring degraded land. Biological approaches, such as plantation of tress, are adaptive as a better remedial process for improving land degradation. Among them, plantation of bamboo help for rapid colonized in degraded land due to their adaptability as fast growing nature and nutrient conservation ability maintaining microclimate through thick layer of bamboo litter.

There are about 90 genera and 1200 Bamboo species in the world (FAO, 2005). Likewise, 12 genera and 53 species of bamboos are found in Nepal (Das, 2002). The distribution of bamboo in Nepal is from Terai to High Mountain (60$4000 \mathrm{~m}$ ) in natural forest as well as on farmland. Both tropical bamboos of South-East Asia and temperate bamboos of Tibet and Bhutan are found in Nepal (Karki, et al., 1995; Ghimire, 2008).

There are three types of bamboo in Nepal. They are differentiated based on their rhizomes.

(1) Sympodial/ Pachymorph/ clumper,

(2) Amphipodial or intermediate/Amphimorph, and

(3) Monopodial/leptomorph/runner/nonclumper or diffuse.

Most of the bamboo species in Nepal have sympodial/pachymorph type rhizomes (clumpforming). They have short and thick rhizomes. They cluster together. Large bamboo species under two genera (Bambusa and Dendrocalamus), and other smaller ones (Thamnocalamus and Drepanostachyum) fall in this category (Jackson, 1994). The rhizomes of amphipodial bamboos exhibit both running (leptomorph) and clumping (pachymorph) habits such as in Melocanna species. Monopodial bamboo has thin and longrhizomes such as species of Phyllostachys which run parallel to the ground, and produce isolated shoots at an interval of up to $3 \mathrm{~m}$.

Among them, monopodial bamboo has shown the best performance for restoration of degraded land. Moso bamboo (Phyllostachys pubescens) is a light demander species. It possesses

Department of Forest Research and Survey, Babarmahal, Kathmandu, Nepal.*E-mail: gopalgt@yahoo.com 
monopodial character; grows in scattered state, and can spread over a large distance and areas. Within the Moso bamboo distribution zone, soil types vary from red soils over yellow soils to yellowish brown soils. Red soils are dominant in the distribution area, whereas suitable conditions include 60 centimeters of deep fertile loam with a $\mathrm{pH}$ ranging from 4.5 to 7.0. Moist conditions are favourable, but not water-logged soil. The growth of Moso bamboo is seriously affected if the salt content of the soil solution is higher than $1 \%$ or if the $\mathrm{pH}$ value exceeds 8.0 (Chen and Wang, 2016). Southern slopes offer better growth conditions for Moso bamboo than northern and south eastern slopes, even though these are still more favorable than north western slopes. Ravine, piedmont and gentle slope are favorable sites for Moso growing (Chen and Wang, 2016).

\section{Materials and methods}

\section{Study area}

The research plot is located at Dhaneshwor Baikiwa Community Forest in Kavrepalanchok district in Mid-hills of Nepal (Fig. 1). Its altitude is $1520 \mathrm{~m}$ above sea level. The latitude of the plot varies from $27^{\circ} 37^{\prime} 00^{\prime \prime}$ to $27^{\circ} 37^{\prime} 30^{\prime \prime} \mathrm{N}$ and the longitude ranges from $31^{\prime} 22^{\prime \prime}-85^{\circ} 32^{\prime} 00^{\prime \prime}$ E. The average annual rainfall is $1300 \mathrm{~mm}$ and seven months are dry from November to May. The mean maximum temperature and minimum temperature are $33^{\circ} \mathrm{C}$ and $4{ }^{\circ} \mathrm{C}$, respectively. The average slope is $20^{\circ}$ and the aspect is northeast. The forest adjoining to the plot is SchimaCastanopsis and pine mixed forest with frequent shrubby patches and poles.

This site consists of brown clayey and sandy loam soil with good drainage. The moisture content and soil thickness of the plot is higher on southern side than northern side, which is exposed and dry. The $\mathrm{pH}$ value of the plot ranges from 4.5 to 5.05 and organic matter per cent ranges from 1.75 to 4.37 and nitrogen percent from 0.13 to 0.18 .
Moso Bamboo Research Study Area

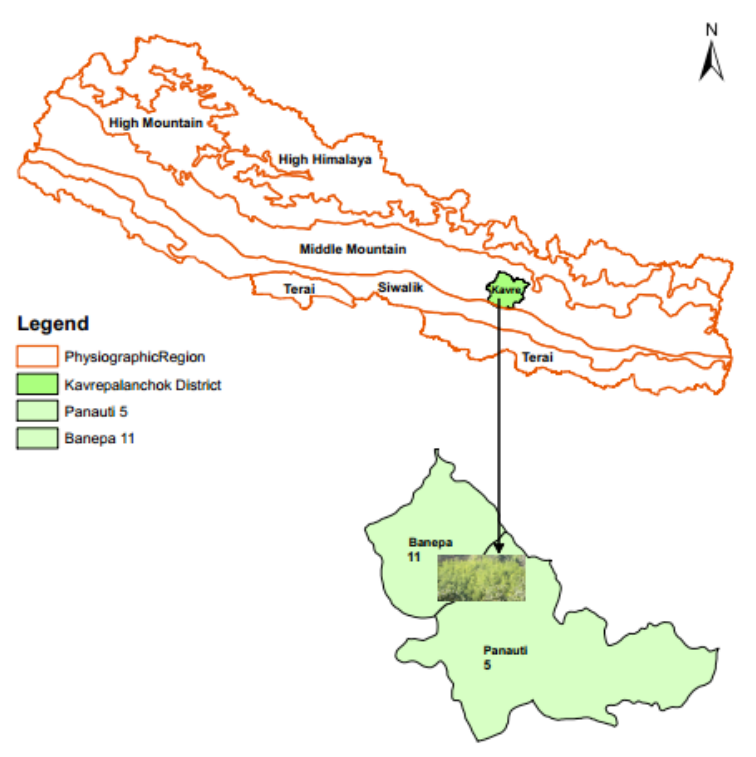

Fig. 1: Map showing Moso bamboo research plot

\section{Acquisition of seeds and seedlings production of Moso bamboo}

The seeds of Moso bamboo were acquired from China in 2006 for research purpose and seedlings were raised in Chalnakhel nursery of Department of Forest Research and Survey (DFRS).

\section{Establishment of trial plot}

The following activities were carried out before plantation.

- Site clearance (bush cleaning)

- Fencing using cement poles and barbed-wire

- Digging out of pits with size of $45 \mathrm{~cm} \mathrm{x} 45$ $\mathrm{cm} \times 45 \mathrm{~cm}$

- Grading of Moso bamboo seedlings in nursery

- Use of cow dung manure (2 kg per pit)

Five-hundred Moso bamboo seedlings were planted in an area of 0.5 ha at a spacing of $3 \mathrm{~m} \times 3$ $\mathrm{m}$ in August 2007 to test the survival and growth. Weeding was done two times a year up to three years. The activities carried out after planting Moso bamboo were as follows: 
- Replacement in September, 2007 (42 plants)

- Watering on the plants during dry season; the pipes were used to carry the water from the tank near to the plot.

- The plants started to wilt and die after one month of planting due to white grubs; use of insecticide,Phorate (powder form) 5-7 gram by making small 3-4 holes around the plant, controlled.

- Use of cow dung manure (3 $\mathrm{kg}$ per plant) in March 2008

- Use of cow dung manure (3 $\mathrm{kg}$ per plant) in May 2009

- Thinning carried out in 2014, 2015, 2016 and found 1980, 2142 and 2438 number of culms as intermittent yield, respectively.

- Rodents control from 2012 and up to date by using Mortein Power guard.

- Mesh wire fencing to control wild boars in 2015.

Dead, dying and drying culms were removed every year. New shoots were counted; diameter at breast height (DBH) and height were measured in different years.

\section{Results and discussion}

At 4.5 months, $96 \%$ Moso bamboo seedlings were found to be survived and the mean height was 21 $\mathrm{cm}$. The survival percentage of seedlings reduced to $92 \%$ at 1.75 ( 1 year 9 months) years and the average height was $1.2 \mathrm{~m}$ at that age. The average number of total culms and new culms per clump at 1.75 years was 9 and 4 , respectively. Still, the Moso bamboo plants were grown in a clustered form i.e. clump. After five years of plantation, 6383 individual culms were recorded whereas it was 6327 individual culms excluding thinned culms. The number of thinned culms was 1980 , 2142, 2438 in 2014, 2015 and 2016, respectively. These results indicated that the Moso bamboo has produced significant number of new culms in such a degraded site. Similarly, the maximum DBH of the new culm was found to be $8.6 \mathrm{~cm}$ in 2017, i.e. after 10 years.

Besides its ecological and economical values, it is taken as biological measures for soil conservation due to its silvicultural characteristics. Evergreen leaves with dense foliage, production of numerous culms, a capacity for rainfall interception and a thick layer of litter maintains a microclimate in the understory for soil moisture retention. Water holding capacity of the litter layer enhances the soil infiltration properties. Better infiltration capacity of Moso bamboo reduces the surface flow and peak run-off.

Development of rhizome, culm and stand are related to the overall growth of Moso bamboo. Its active rhizomatous clonal growth produces rapid, widespread expansion of ramets to develop the below-ground lateral rhizome system. Young culms are formed by the elongation of internodes from buried rhizome into the soil. That individual clump produces a multiple culms in the following year and forms a stand with differently aged culms distributed throughout to make an uneven aged bamboo forest structure.

\section{Conclusion}

The recorded stand density reflects that the degraded land of Dhaneshwor Baikiwa Community Forest is converted to productive forest land through restoration from Moso bamboo plantation. After the successful establishment of Moso bamboo in a research plot on the degraded site of community forest land, it is recommended as a suitable bamboo species for the ecological restoration and reclamation of degraded land in the Mid-hills of Nepal. Due to soil binding capacity, Moso bamboo can be introduced for the treatment of earthquake induced landslide and soil liquification. The side effect of exotic species should be examined before introducing it to the new site. More intensive research, investment and up scaling is recommended in other parts of Nepal.

\section{References}

Acharya, A. K. and Kafle, N. 2009. Land degradation issues in Nepal and its management through agroforestry. Journal of Agriculture and Environment 10: 115-123.

Adhikari, N. 2008. Economic Potential of Bamboo in Nepal: For the Traditional Bamboo Users in the Modern Economy (http://abari.org/ economic-potential-of-bamboo-innepal).

Bai, Z. G., Dent, D. L., Olsson, L. and Schaepman, M. E. 2008. Global Assessment 
of Land Degradation and Improvement. 1 . Identification by remote sensing. Report 2008/01, ISRIC - World Soil Information, Wageningen. USA

Chen, T. and Wang, D. 2016. The Trend of Growth Characteristics of Moso bamboo (Phyllostachys pubescens) forests under an unmanaged Condition in Central Taiwan. Taiwan J For Sci 31(2), pp. 75-87.

Das, A. N. 2002. Bamboo growing and its market development potential for sustaining rural livelihood and poverty reduction in eastern Nepal. Banko Janakari 12 (1): 8-19.

FAO. 2005. State of the World's Forest. Food and Agriculture organization of the United States, Rome, Italy.

Ghimire, A. 2008. An Assessment of the Dependency of Farmers on Bamboo Resource for Rural Livelihood in Lalitpur District, Nepal. M.Sc. Thesis, BOKU University, Vienna, Austria.
Howell, J. H., Sunwar, I. and Clark, J. E. 1989. Role of Vegetation in Slope Stabilisation on Highways. Department of Roads, HMGN, Nepal.

Karki, M. B and Karki, J. B. S. 1995. National bamboo and rattan information database, Nepal. Tribhuvan University, Institute of Forestry, Pokhara, Nepal.

Narayana, V. V. D. 1988. Watershed development and resource conservation for rangeland improvements. In Rangeland Resource and Management (ed.) Singh, P., Proceedings of the National rangeland Symposium. November 9-12, 1987, IGFRI, Jhansi, India, 229-237.

Stapleton, C. M. A. 1994. Bamboos. In Manual of Afforestation in Nepal, Volume 2 (ed.) Jackson, J. K., Forest Research and Survey Centre. Ministry of Forests and Soil Conservation, Kathmandu, 401-426.

Ueda, K. 1974. Bamboo. Kenshu-In 31: 13-20. 